\title{
Entropy-Aided Assessment of Amla (Emblica officinalis) Quality Using Principal Component Analysis
}

\author{
Alok Mukherjee ${ }^{1}$, Kingshuk Chatterjee ${ }^{1}$, Tanmay Sarkar 2,* (D) \\ 1 Government College of Engineering and Ceramic Technology, Kolkata, India \\ 2 Malda Polytechnic, West Bengal State Council of Technical Education, Govt. of West Bengal, Malda-732102, India \\ * Correspondence: tanmays468@gmail.com (T.S.);
}

Scopus Author ID 57203373596

Received: 31.03.2021; Revised: 5.05.2021; Accepted: 8.05.2021; Published: 18.06.2021

\begin{abstract}
The texture analysis-based scheme for identifying non-consumable amla fruit (Emblica officinalis) samples is proposed here. The method uses entropy analysis to detect wrinkles and irregularities developed on the fruit surface with progression in time. Since entropy is one of the major tools used to detect the randomness of data, it is used here to identify these surface irregularities, which are almost absent in fresh samples. Based on these features, the edibility of the samples is predicted. Principal component analysis (PCA) further analyzes these entropy features to enhance the most important directions of variations, followed by a threshold-based segmentation scheme to detect rotten samples. The method possesses less computational burden as it applies PCA and entropy only; it is highly efficient to yield a high detection accuracy of $93.33 \%$; hence, it is easy for real-life implementation.
\end{abstract}

Keywords: multivariate analysis; image analysis; smartphone; food technology; machine vision.

(C) 2021 by the authors. This article is an open-access article distributed under the terms and conditions of the Creative Commons Attribution (CC BY) license (https://creativecommons.org/licenses/by/4.0/).

\section{Introduction}

Identification of the quality of fruits is of major importance in the field of research. This is more important for identifying non-consumable fruit samples: both for bulk production in factories and for direct consumer applications. This task is quite challenging, as the same fruit or vegetable possesses many varieties that are different in color, shape, and texture, especially as ripeness varies. Another challenge lies in the dissimilarity of methods for image acquisition $[1]$.

Colour and texture analysis are the most common methods employed to detect rotten samples among a bulk of fruits. The color pattern and intensity change progressively; as well as, wrinkles and other discolored patches are also developed on the surface of the fruits as these rotten gradually. Researchers have analyzed both the hue-saturation-intensity pattern [2] or the red-green-blue (RGB) space $[3,4]$ to identify features. Entropy has always been an effective tool for the detection of the randomness of data. The surface texture irregularities develop severe randomness as the surface wrinkles and develop dark patches and lines. A similar entropy-based feature extraction method of food image has been considered for dietary assessment [5], though there is a lesser number of evidence for entropy consideration for food image analysis. In this work, we have studied the surface of the Amla fruits using the entropy filtering method to extract irregular features. These features are further analyzed using principal component analysis (PCA), a multivariate statistical model to identify the key directions of 
variation of the entropy features, reducing the data set's dimension. Analysis in this work has shown that the application of PCA over these entropy values allows for enhanced segmentation of the 'consumable' and 'non-consumable' classes of fruit samples. PCA has also been applied in abundance in agricultural researches, especially for defect detection works, incorporating image analysis of different fruits [6] and vegetables like orange and mandarin [7], mushrooms [8], peaches [9], cucumbers [10], nuts [11] and apple [12-15]. Hybrid analysis of PCA with other methods like multi-class kernel support vector machine (kSVM) [16], hierarchical cluster analysis (HCA) [17], wavelet entropy and neural network [18] and several others have been developed over the years. Researchers considered kernel PCA, especially for multivariate image analysis (MIA) [19]. Researchers have proposed efficient bruise detection methods of fruits using a multi-tool model including PCA [20-22].

Many other methodologies, apart from PCA, are also used in a huge number of researches. The latest development of soft computational methods has given a huge rise in the use of several techniques in food quality assessment. Advanced recently developed methods like deep neural networks have been investigated in good numbers in recent research [23-25]. Many other works have concentrated on analyzing the geometrical characteristics of fruits and vegetables, including their area and perimeter etc. [26-28]. Other latest methods include the application of Hopfield networks [29]. Quality assessment of foods during various storage conditions is also analyzed using the image processing technique [30]. In the present work, although, we have used only PCA-based features, aided by entropy analysis, to develop an efficient amla fruit quality determining algorithm.

The proposed work incorporates entropy features and PCA to develop a threshold-based binary classification of amla fruits to detect non-consumable samples. The method is easy in computation as it uses only PCA and entropy filtering and avoids using computationally heavier methods like the supervised learning models using neural networks, requiring large training or the transform-based models like wavelet or Fourier based spectrum analyses, which are other extremely used models. More importantly, use only the first PC reduces the computation and dimensionality of the model. The effectiveness of the proposed model is also highlighted by its high accuracy of $93.33 \%$ for defect detection. Besides, the present scheme doesn't use any pre-filter to pre-process the image, which further reduces the complexity of analysis. Finally, the use of smartphones for taking images ensures the on-site availability and portability of the proposed quality assessment model. A few of the researches with their methodologies and parameters considered are described in Table 1.

Table 1. Researches in the field of image analysis for food samples using multivariate analysis.

\begin{tabular}{|c|c|c|c|c|c|c|}
\hline Sl no. & Sample & Objective & Image acquisition & Method used & Parameters considered & Ref. \\
\hline 1 & $\begin{array}{l}\text { pesto } \\
\text { sauce }\end{array}$ & $\begin{array}{l}\text { Automated food } \\
\text { colour evaluation }\end{array}$ & $\begin{array}{l}\text { common digital } \\
\text { camera }\end{array}$ & PCA & $\mathrm{R}, \mathrm{G}, \mathrm{B}$ values & [4] \\
\hline 2 & Orange & Skin defects detection & $\begin{array}{l}\text { charge-coupled } \\
\text { camera }\end{array}$ & PCA & Colour and texture & [7] \\
\hline 3 & $\begin{array}{l}\text { Left over } \\
\text { food stuff }\end{array}$ & $\begin{array}{l}\text { Identification of } \\
\text { traces of packaging } \\
\text { material in food }\end{array}$ & $\begin{array}{ll}\text { stereomicroscope } \\
\text { coupled with a } \\
\text { digital camera }\end{array}$ & PCA & $\begin{array}{l}\mathrm{R}, \mathrm{G}, \mathrm{B} \text { followed by } \\
\text { color grams }\end{array}$ & [31] \\
\hline 4 & Corn & $\begin{array}{l}\text { Mass and volume } \\
\text { measurement }\end{array}$ & $\begin{array}{l}\text { conventional } \\
\text { scanner }\end{array}$ & $\begin{array}{l}\text { partial least } \\
\text { squares (PLS) }\end{array}$ & $\begin{array}{l}\mathrm{R}, \mathrm{G}, \mathrm{B} \text { and } \mathrm{H}, \mathrm{S}, \mathrm{V} \\
\text { values }\end{array}$ & [32] \\
\hline 5 & $\begin{array}{l}\text { Tartrazine, } \\
\text { Allura red } \\
\end{array}$ & $\begin{array}{l}\text { Detection of artificial } \\
\text { food colorant }\end{array}$ & flatbed scanner & PLS & $\begin{array}{l}\text { HSV, Lab, YCBCR and } \\
\text { CMYK values }\end{array}$ & {$[33]$} \\
\hline 6 & maize & $\begin{array}{ll}\text { Quantification } & \text { of } \\
\text { defective kernels }\end{array}$ & Digital camera & PLS & $\begin{array}{l}\mathrm{R}, \mathrm{G}, \mathrm{B} \text { followed by } \\
\text { color grams }\end{array}$ & [34] \\
\hline 7 & Soft drinks & $\begin{array}{l}\text { Sunset yellow in soft } \\
\text { drinks }\end{array}$ & $\begin{array}{l}\text { Fluorescent lamps } \\
\text { illuminated sample; } \\
\text { CCD digital camera }\end{array}$ & $\begin{array}{l}\text { Multivariate } \\
\text { Linear } \\
\text { Regression }\end{array}$ & $\mathrm{L}, \mathrm{a}, \mathrm{b}$ values & [35] \\
\hline
\end{tabular}




\begin{tabular}{|c|c|c|c|c|c|c|}
\hline SI no. & Sample & Objective & Image acquisition & Method used & Parameters considered & Ref. \\
\hline 8 & $\begin{array}{l}\text { Vitaminsu } \\
\text { pplement } \\
\text { tablets }\end{array}$ & Iron quantification & $\begin{array}{l}\text { smartphone } \\
\text { operating } \\
\text { Android } 4.3\end{array}$ & PCA & $\mathrm{R}, \mathrm{G}, \mathrm{B}$ values & [36] \\
\hline 9 & hazelnut & Defect detection & Digital camera & $\begin{array}{l}\text { PLS-DA, } \\
\text { interval-PLS- } \\
\text { DA }\end{array}$ & $\begin{array}{l}\mathrm{R}, \mathrm{G}, \mathrm{B} \text { followed by } \\
\text { colourgrams }\end{array}$ & [37] \\
\hline 10 & $\begin{array}{l}\text { green } \\
\text { coffee }\end{array}$ & Defect detection & $\begin{array}{l}\text { Near Infra Red } \\
\text { Spectral Scanner }\end{array}$ & PCA, PLS-DA & Wave number & {$[38]$} \\
\hline 11 & Raw ham & $\begin{array}{l}\text { Red skin Defect } \\
\text { detection }\end{array}$ & Digital camera & PLS-DA & $\begin{array}{l}\mathrm{R}, \mathrm{G}, \mathrm{B} \text { followed by } \\
\text { colourgrams }\end{array}$ & [39] \\
\hline 12 & pig fat & $\begin{array}{l}\text { Classification of fat } \\
\text { samples }\end{array}$ & $\begin{array}{l}\text { Near Infra Red } \\
\text { Spectral Scanner }\end{array}$ & PCA, PLS-DA & Wave number & {$[40]$} \\
\hline 13 & $\begin{array}{l}\text { pesto } \\
\text { sauce }\end{array}$ & $\begin{array}{l}\text { Sensory and } \\
\text { compositional } \\
\text { parameters }\end{array}$ & $\begin{array}{l}\text { tungsten lamp } \\
\text { illuminated sample; } \\
\text { digital camera }\end{array}$ & PLS & $\mathrm{R}, \mathrm{G}, \mathrm{B}$ values & [41] \\
\hline 14 & $\begin{array}{l}\text { mushroom } \\
\mathrm{s}\end{array}$ & Bruise detection & $\begin{array}{l}\text { line-scanning } \\
\text { Hyperspectral image } \\
\text { instrument }\end{array}$ & PCA & Wave number & [8] \\
\hline 15 & $\begin{array}{l}\text { gulupa } \\
\text { (Passiflora } \\
\text { edulis } \\
\text { Sims. fo } \\
\text { edulis) }\end{array}$ & Ripeness & Digital camera & PCA & Hue angle, chroma & {$[42]$} \\
\hline
\end{tabular}

\section{Materials and Methods}

We have collected five samples of fresh amla samples on day 1 and keep these at room temperature $\left(25 \pm 5{ }^{\circ} \mathrm{C}\right)$, away from direct sunlight. The samples are allowed to degrade in quality, and images have been captured daily thrice daily [43,44]. The samples started to degrade in quality as these developed dark patches all over the surface; as well as, the skins of the samples also became wrinkled progressively. The hedonic scale has been used to evaluate the samples manually $[17,45]$ when it was found that the samples were at the freshest most condition during days 1 and 2, when the scale was above 8 units. These are denoted as 'Fresh' samples. From the 7th day onwards, the quality degraded to below 5 units, when these were declared to be 'Rotten'. During the intermediate days, i.e., days 3 to 6 , the samples were mentioned as 'Intermediate'. In this work, we have considered the first two classes together as 'Consumable' class, and the 'Rotten' class as 'Non-Consumable' class; thus, paving the way for a binary classifier model for 'Non-Consumable' sample detection.

We have cropped the image from the center part of it to accommodate the maximum area of the fruit surface, followed by resizing the same to a $300 \times 300$ image. We have tried to accommodate approximately the highest possible square at the round amla fruit image center.

The three-layer Red-Green-Blue (RGB) image is then converted to a grayscale image for texture analysis. This conversion further reduces the image to 33\% approximately since it merges the three independent layers to a single grayscale layer; thereby, further reducing the computational burden.

\section{Results and Discussion}

Entropy filtering is applied here when the image is scanned by using a 9-by-9 matrix to find out the entropy value of the 9-by-9 neighborhood around each pixel, thus forming an entropy array for each row and column; using symmetric padding at borders. Hence, it yields another matrix of the same dimension, denoted as entropy matrix; although, not an exact image since the entropy values are floating. Hence, the entropy matrix is scaled using expression (1) as shown below: 
$[E] 300 \times 300=$ Entropy filtering of the image matrix [I] 300 $\times 300$;

where, $E$ is the entropy matrix of the image $I$. Each element of this entropy matrix is scaled to develop the entropy image $(F)$ using the following expression as:

$f_{i}=\left(e_{i}-e \_\right.$max $) /\left(e \_\right.$max $-e \_$min $) ;$

where, $e_{i}$ is the $i$-th element of the entropy matrix $(E) ; e_{-} \max$ and $e_{-}$min are the maximum and minimum values; and $f_{i}$ is the $i$-th element of the entropy image $(F)$. Hence, $F$ becomes another $300 \times 300$ image, shown in Figure 1.
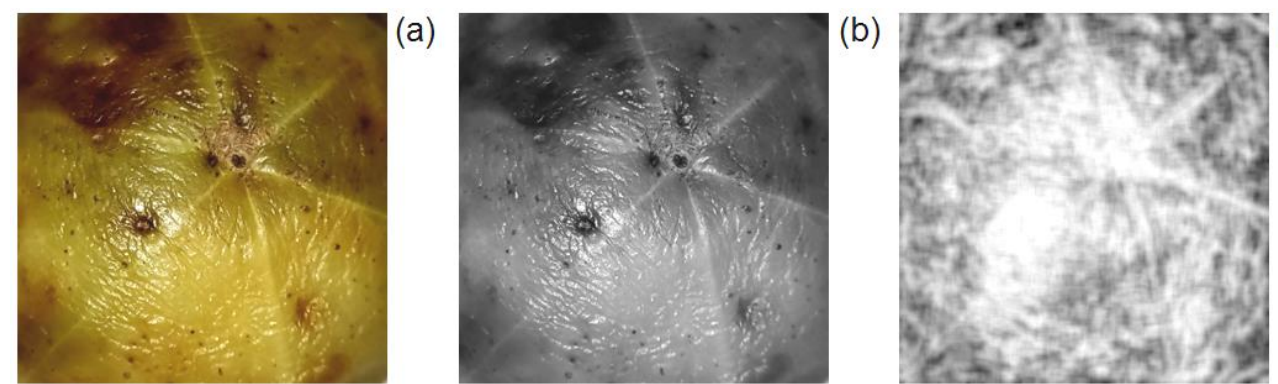

Figure. 1. (a) Centered cropped image, (b) grayscale converted image, (c) entropy image

Finally, PCA is applied over the entropy histogram to obtain PC scores, each score point indicating image. The first PC is only considered here, which is found to provide sufficient distinguishing features. These features are compared to provide segmentation between the 'Consumable' and 'Non-Consumable' classes. The steps associated with the design of the algorithm are shown in the form of a flow diagram in Figure 2.

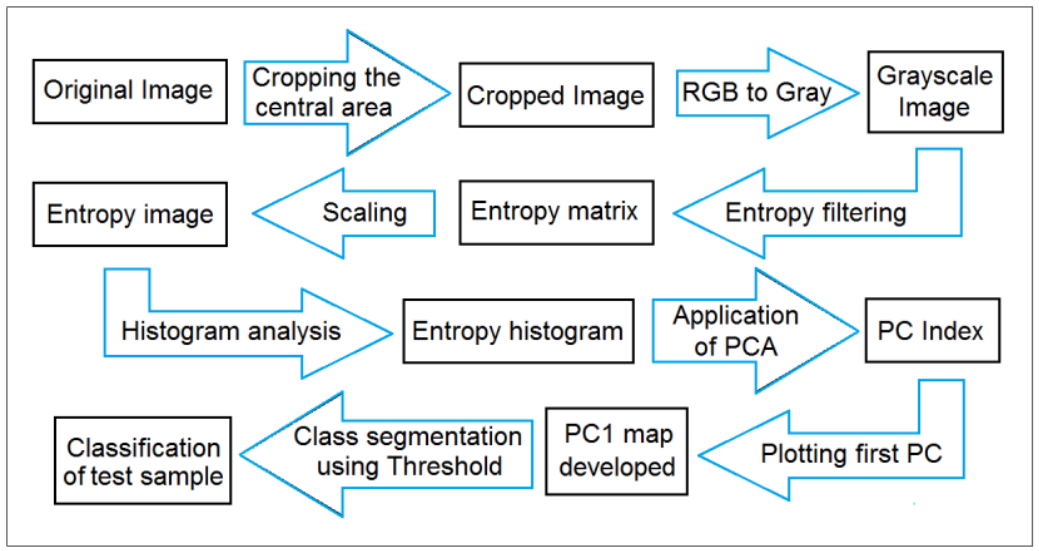

Figure 2. Flow diagram of the proposed algorithm.

The histogram of the total 45 samples is shown in Figure 3(a); where we have taken 15 samples from each 'Fresh', 'Intermediate' and 'Rotten' categories. The average level of these three classes is further shown independently in Figure 3(b), which shows a large overlap between each class; although, the nature of the 'Rotten' class is shifted more towards the highintensity value.
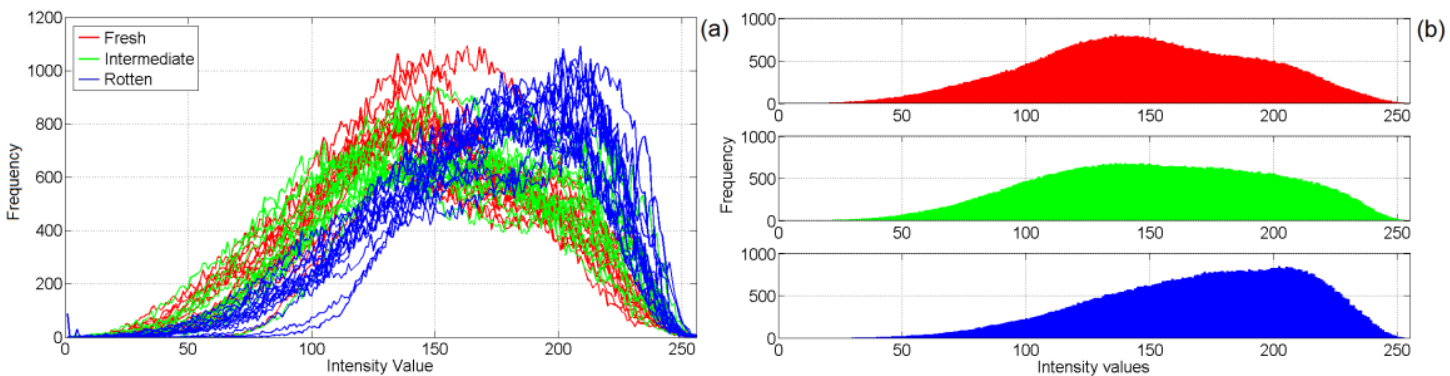

Figure 3. (a) Frequency distribution of intensity values of three classes, (b) average representation. 
The first PC indices (PC1) are found for each sample image; i.e., each image is represented by a single $\mathrm{PC} 1$ point. We have found out that only $\mathrm{PC} 1$ is significant enough to segregate 'Consumable' and 'Non-Consumable' categories. The distribution of training samples is illustrated in Table 2 and in Figure 4.

Table 2. Training data set description.

\begin{tabular}{c|c|c|c}
\multirow{2}{*}{ Class } & \multicolumn{2}{|c|}{ Consumable } & Non-Consumable \\
\cline { 2 - 4 } & Fresh & Intermediate & Rotten \\
\hline Day of progression & 1,2 & 3 to 6 & 7,8 \\
\hline \multirow{2}{*}{ Number of samples } & 15 & 30 & 15 \\
\cline { 2 - 4 } & \multicolumn{2}{|c}{45}
\end{tabular}

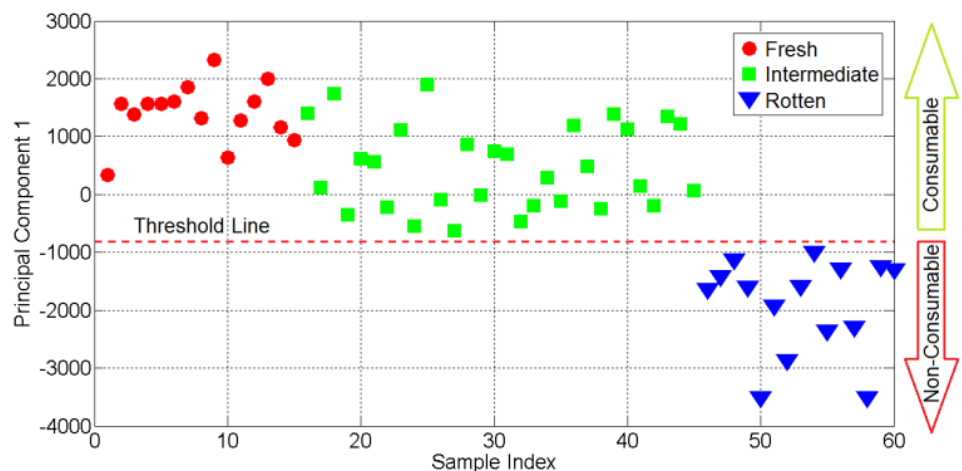

Figure 4. Segmentation of PC1 index of 'Consumable' and 'Non-Consumable' classes using a threshold.

It is observed from Figure 4 that entropy-PCA index of samples belonging to the 'Consumable' and 'Non-Consumable' classes could be separated using a 'Threshold Line', as shown using a dotted line. The PC1 points belonging to 'Consumable' class mostly cluster above the threshold line; whereas, the same for the 'Non-Consumable' class lies below. It is further observed that the distribution of points belonging to the two classes leaves a very narrow band in between. These PC1 values of the two classes are also analyzed using boxplots, as shown in Figure 5 to compare their distribution. It is observed from here that the threshold line is able to segregate the 'Consumable' and 'Non-Consumable' classes distinctly without any overlap; although, the margin of separation is very narrow. But the median values of the two classes are well apart. This shows the usefulness of such threshold-based analysis. The test sample is analyzed similarly and the entropy-PCA index is observed to locate its position above or below the threshold; thus, determining the class.

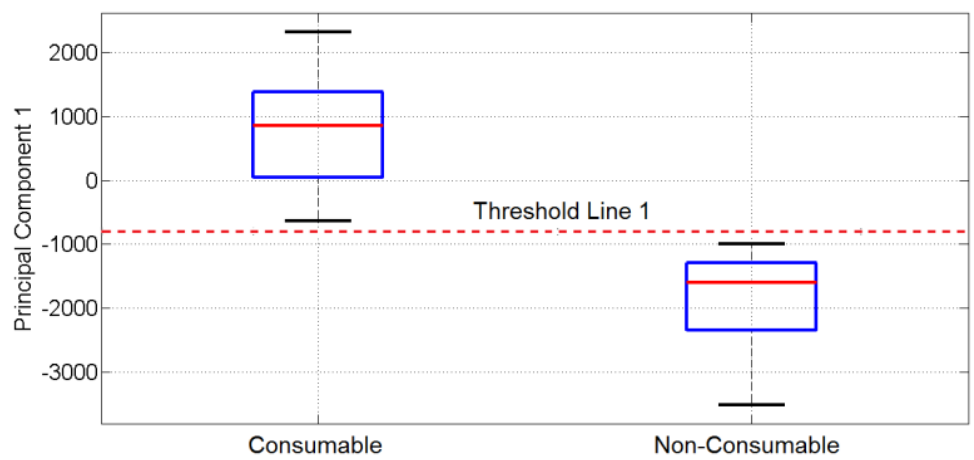

Figure 5. Segmentation of entropy-PCA index values of 'Consumable' and 'Non-Consumable' classes.

The effectiveness of using PCA over the entropy features is illustrated in Figure 6; which shows the average entropy histograms of 'Consumable' and 'Non-Consumable' classes, along with the corresponding boxplots. Figure 6(a) shows that there is major overlap considering the intensity values of both classes. Figure 6(b) shows the overlap in magnitudes of histograms. These major overlap in either axis shows marginal ineffectiveness of using 
entropy features only. Application of PCA over these features broadly segments the two classes without any overlap. Comparing the two boxplots, i.e., Figure 5 with that of Figure 6(b), shows this distinction prominently, displaying the effectiveness of using PCA over the entropy features.
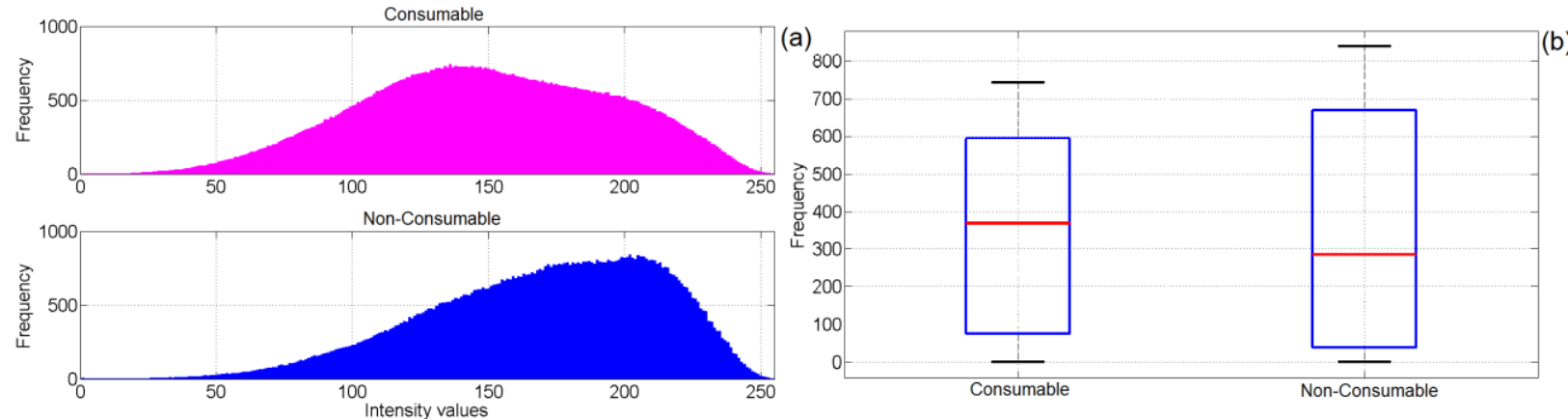

Figure 6. (a) Entropy histogram of 'Consumable' and 'Non-Consumable' classes (b) corresponding boxplots.

The Proposed model is tested with the remaining 60 fruit image samples. The test results are shown in Table 3, which shows that the proposed model detects the classes very accurately. It is found that 56 out of the 60 test cases are identified correctly, yielding an overall accuracy of $93.33 \%$.

Table 3. Classifier outcomes.

\begin{tabular}{c|c|c|c}
\multirow{2}{*}{ True Class } & \multicolumn{2}{|c|}{ Predicted Class } & \multirow{2}{*}{ Total } \\
\cline { 2 - 3 } & Consumable & Non-Consumable & 45 \\
\hline Consumable & 43 & 2 & 15 \\
\hline Non-Consumable & 2 & 13 &
\end{tabular}

The efficiency of classification is further evaluated with the following metrics:

Accuracy $(\%)=($ True Positive + True Negative $) /($ True Positive + False positive + False Negative+True Negative)

Specificity $(\%)=$ True Negative $/($ True Negative + False Positive)

Sensitivity $(\%)=$ True Positive $/($ True Positive + False Negative $)$

Precision $(\%)=$ True Positive $/$ (True Positive + False Positive $)$

F-score $=2 *($ Sensitivity $*$ Precision $) /($ Sensitivity + Precision $)$

Table 4 represents the measure for the performance of the methodology proposed. The high F-score signifies the robustness of the classifier; overall accuracy of 93.33\% indicates the lower rate of errors. The higher overall specificity and sensitivity indicate accurate predictability of the target class. Both these parameters indicate the model's competency to differentiate between 'Consumable' and 'Non-Consumable' fruits.

Table 4. Performance analysis of the entropy based PCA model.

\begin{tabular}{c|c|c|c|c|c} 
Parameter & F-score & $\begin{array}{c}\text { Accuracy } \\
(\%)\end{array}$ & $\begin{array}{c}\text { Specificity } \\
(\%)\end{array}$ & $\begin{array}{c}\text { Sensitivity } \\
(\%)\end{array}$ & $\begin{array}{c}\text { Precision } \\
(\%)\end{array}$ \\
\hline Consumable & 95.55 & 93.33 & 86.67 & 95.55 & 95.55 \\
\hline Non-Consumable & 86.67 & 93.33 & 95.55 & 86.67 & 86.67
\end{tabular}

\section{Conclusions}

A texture analysis method using entropy and PCA has been proposed here to identify amla fruits' edibility. Only the first principal component has been considered here to develop a threshold-based classification scheme. This segregates the samples into Consumable' and 'Non-Consumable' classes. The method is simple since it uses entropy and PCA as the major 
feature extractor and doesn't include supervised learning or mathematically heavier transformbased methods. Besides, non-use of any pre-filter further enhances computational ease. Finally, the proposed model is highly effective with more than $93 \%$ accuracy of freshness detection, suggesting the possibility of real-life implementation of the algorithm.

\section{Funding}

This research received no external funding.

\section{Acknowledgments}

The authors want to acknowledge the O.I.C., other staff members and Ms Sukannya Dutta ( $3^{\text {rd }}$ year student of Malda Polytechnic) Malda Polytechnic, West Bengal, India, for their support.

\section{Conflicts of Interest}

The authors declare no conflict of interest.

\section{References}

1. Dubey, S.R.; Jalal, A.S. Application of Image Processing in Fruit and Vegetable Analysis: A Review. J. Intell. Syst. 2015, 24, 405-424, https://doi.org/10.1515/jisys-2014-0079.

2. Danti, A.; Madgi, M.; Anami, B.S. Mean and range color features based identification of common Indian leafy vegetables. Int. J. Signal Process. Image Process. Pattern Recognit. 2012, 5, 151-160.

3. Dubey, S.R.; Jalal, A.S. Robust Approach for Fruit and Vegetable Classification. Procedia Eng. 2012, 38 , 3449-3453, https://doi.org/10.1016/j.proeng.2012.06.398.

4. Antonelli, A.; Cocchi, M.; Fava, P.; Foca, G.; Franchini, G.C.; Manzini, D.; Ulrici, A. Automated evaluation of food colour by means of multivariate image analysis coupled to a wavelet-based classification algorithm. Anal. Chim. Acta 2004, 515, 3-13, https://doi.org/10.1016/j.aca.2004.01.005.

5. Zhu, F.; Bosch, M.; Khanna, N.; Boushey, C.J.; Delp, E.J. Multiple Hypotheses Image Segmentation and Classification With Application to Dietary Assessment. IEEE J. Biomed. Heal. Informatics 2015, 19, 377388, https://doi.org/10.1109/JBHI.2014.2304925.

6. Farrugia, J.; Griffin, S.; Valdramidis, V.P.; Camilleri, K.; Falzon, O. Principal component analysis of hyperspectral data for early detection of mould in cheeselets. Curr. Res. Food Sci. 2021, 4, 18-27, https://doi.org/10.1016/j.crfs.2020.12.003.

7. López-García, F.; Andreu-García, G.; Blasco, J.; Aleixos, N.; Valiente, J.-M. Automatic detection of skin defects in citrus fruits using a multivariate image analysis approach. Comput. Electron. Agric. 2010, 71, 189197, https://doi.org/10.1016/j.compag.2010.02.001.

8. Gowen, A.A.; O’Donnell, C.P.; Taghizadeh, M.; Cullen, P.J.; Frias, J.M.; Downey, G. Hyperspectral imaging combined with principal component analysis for bruise damage detection on white mushrooms (Agaricus bisporus). J. Chemom. 2008, 22, 259-267, https://doi.org/10.1002/cem.1127.

9. Sun, Y.; Wei, K.; Liu, Q.; Pan, L.; Tu, K. Classification and Discrimination of Different Fungal Diseases of Three Infection Levels on Peaches Using Hyperspectral Reflectance Imaging Analysis. Sensors (Basel). 2018, 18, https://doi.org/10.3390/s18041295.

10. Liu, Y.; Chen, Y.R.; Wang, C.Y.; Chan, D.E.; Kim, M.S. Development of hyperspectral imaging technique for the detection of chilling injury in cucumbers; spectral and image analysis. Appl. Eng. Agric. 2006, 22, 101-111.

11. Han, Y.; Liu, Z.; Khoshelham, K.; Bai, S.H. Quality estimation of nuts using deep learning classification of hyperspectral imagery. Comput. Electron. Agric. 2021, 180, 105868, https://doi.org/10.1016/j.compag.2020.105868.

12. Zhu, B.; Jiang, L.; Luo, Y.; Tao, Y. Gabor feature-based apple quality inspection using kernel principal component analysis. J. Food Eng. 2007, 81, 741-749.

13. Peterson, B.B.D.; Tabb, A. Identifying apple surface defects using principal components analysis and artificial neural networks. Trans. ASABE 2007, 50, 2257-2265.

14. Bhargava, A.; Bansal, A. Machine learning based quality evaluation of mono-colored apples. Multimed. Tools Appl. 2020, 79, 22989-23006, https://doi.org/10.1007/s11042-020-09036-9.

15. Fan, S.; Li, J.; Zhang, Y.; Tian, X.; Wang, Q.; He, X.; Zhang, C.; Huang, W. On line detection of defective apples using computer vision system combined with deep learning methods. J. Food Eng. 2020, 286, 110102, https://doi.org/10.1016/j.jfoodeng.2020.110102. 
16. Zhang, Y.; Wu, L. Classification of fruits using computer vision and a multi-class support vector machine. Sensors (Basel). 2012, 12, 12489-12505, https://doi.org/10.3390/s120912489.

17. Granato, D.; Santos, J.S.; Escher, G.B.; Ferreira, B.L.; Maggio, R.M. Use of principal component analysis (PCA) and hierarchical cluster analysis (HCA) for multivariate association between bioactive compounds and functional properties in foods: A critical perspective. Trends Food Sci. Technol. 2018, 72, 83-90, https://doi.org/10.1016/j.tifs.2017.12.006.

18. Wang, S.; Zhang, Y.; Ji, G.; Yang, J.; Wu, J.; Wei, L. Fruit Classification by Wavelet-Entropy and Feedforward Neural Network Trained by Fitness-Scaled Chaotic ABC and Biogeography-Based Optimization. Entropy 2015, 17, https://doi.org/10.3390/e17085711.

19. Tao, P.; Feng, X.; Wen, C. Image Recognition Based on Two-Dimensional Principal Component Analysis Combining with Wavelet Theory and Frame Theory. J. Control Sci. Eng. 2018, 2018, 9061796, https://doi.org/10.1155/2018/9061796.

20. Baranowski, P.; Mazurek, W.; Wozniak, J.; Majewska, U. Detection of early bruises in apples using hyperspectral data and thermal imaging. J. Food Eng. 2012, 110, 345-355, https://doi.org/10.1016/j.jfoodeng.2011.12.038.

21. Zhao, J.; Ouyang, Q.; Chen, Q.; Wang, J. Detection of bruise on pear by hyperspectral imaging sensor with different classification algorithms. Sens. Lett. 2010, 8, 570-576, https://doi.org/10.1166/sl.2010.1313.

22. Ariana, D.P.; Lu, R.; Guyer, D.E. Near-infrared hyperspectral reflectance imaging for detection of bruises on pickling cucumbers. Comput. Electron. Agric. 2006, 53, 60-70, https://doi.org/10.1016/j.compag.2006.04.001.

23. Tan, W.; Zhao, C.; Wu, H. Intelligent alerting for fruit-melon lesion image based on momentum deep learning. Multimed. Tools Appl. 2016, 75, 16741-16761, https://doi.org/10.1007/s11042-015-2940-7.

24. Naranjo-Torres, J.; Mora, M.; Hernández-García, R.; Barrientos, R.J.; Fredes, C.; Valenzuela, A. A Review of Convolutional Neural Network Applied to Fruit Image Processing. Appl. Sci. 2020, 10, https://doi.org/10.3390/app10103443.

25. Kakani, V.; Nguyen, V.H.; Kumar, B.P.; Kim, H.; Pasupuleti, V.R. A critical review on computer vision and artificial intelligence in food industry. J. Agric. Food Res. 2020, 2, 100033, https://doi.org/10.1016/j.jafr.2020.100033.

26. Pothen, M.E.; Pai, M.L. Detection of Rice Leaf Diseases Using Image Processing. In Proceedings of the 2020 Fourth International Conference on Computing Methodologies and Communication (ICCMC); 2020; 424430 .

27. Narushin, V.G.; Romanov, M.N.; Lu, G.; Cugley, J.; Griffin, D.K. Digital imaging assisted geometry of chicken eggs using Hügelschäffer's model. Biosyst. Eng. 2020, 197, 45-55, https://doi.org/10.1016/j.biosystemseng.2020.06.008.

28. De Moura Araújo, G.; dos Santos, F.F.L.; de Almeida, S.L.H.; Martins, R.N.; Voltarelli, M.A.; Paixão, C.S.S.; de Assis de Carvalho Pinto, F. Sugarcane Harvesting Quality by Digital Image Processing. Sugar Tech 2021, 23, 209-218, https://doi.org/10.1007/s12355-020-00867-2.

29. Fermo, I.R.; Cavali, T.S.; Bonfim-Rocha, L.; Srutkoske, C.L.; Flores, F.C.; Andrade, C.M.G. Development of a low-cost digital image processing system for oranges selection using hopfield networks. Food Bioprod. Process. 2021, 125, 181-192, https://doi.org/10.1016/j.fbp.2020.11.012.

30. Behera, S.K.; Rath, A.K.; Mahapatra, A.; Sethy, P.K. Identification, classification \& grading of fruits using machine learning \& computer intelligence: a review. J. Ambient Intell. Humaniz. Comput. 2020, https://doi.org/10.1007/s12652-020-01865-8.

31. Calvini, R.; Luciano, A.; Ottoboni, M.; Ulrici, A.; Tretola, M.; Pinotti, L. Multivariate image analysis for the rapid detection of residues from packaging remnants in former foodstuff products (FFPs) - a feasibility study. Food Addit. Contam. Part A 2020, 37, 1399-1411, https://doi.org/10.1080/19440049.2020.1769195.

32. de Camargo, V.R.; dos Santos, L.J.; Pereira, F.M.V. A Proof of Concept Study for the Parameters of Corn Grains Using Digital Images and a Multivariate Regression Model. Food Anal. Methods 2018, 11, 18521856, https://doi.org/10.1007/s12161-017-1028-6.

33. Vidal, M.; Garcia-Arrona, R.; Bordagaray, A.; Ostra, M.; Albizu, G. Simultaneous determination of color additives tartrazine and allura red in food products by digital image analysis. Talanta 2018, 184, 58-64, https://doi.org/10.1016/j.talanta.2018.02.111.

34. Orlandi, G.; Calvini, R.; Foca, G.; Ulrici, A. Automated quantification of defective maize kernels by means of Multivariate Image Analysis. Food Control 2018, 85, 259-268, https://doi.org/10.1016/j.foodcont.2017.10.008.

35. Hosseininia, S.A.R.; Kamani, M.H.; Rani, S. Quantitative determination of sunset yellow concentration in soft drinks via digital image processing. J. Food Meas. Charact. 2017, 11, 1065-1070, https://doi.org/10.1007/s11694-017-9483-8.

36. Helfer, G.A.; Magnus, V.S.; Bock, F.C.; Teichmann, A.; Ferrao, M.F.; Costa, A.B. da PhotoMetrix: An Application for Univariate Calibration and Principal Components Analysis Using Colorimetry on Mobile Devices. J. Braz. Chem. Soc. 2017, 28, 328-335, https://doi.org/10.5935/0103-5053.20160182.

37. Giraudo, A.; Calvini, R.; Orlandi, G.; Ulrici, A.; Geobaldo, F.; Savorani, F. Development of an automated method for the identification of defective hazelnuts based on RGB image analysis and colourgrams. Food 
Control 2018, 94, 233-240, https://doi.org/10.1016/j.foodcont.2018.07.018.

38. Calvini, R.; Foca, G.; Ulrici, A. Data dimensionality reduction and data fusion for fast characterization of green coffee samples using hyperspectral sensors. Anal. Bioanal. Chem. 2016, 408, 7351-7366, https://doi.org/10.1007/s00216-016-9713-7.

39. Ulrici, A.; Foca, G.; Ielo, M.C.; Volpelli, L.A.; Lo Fiego, D. Pietro Automated identification and visualization of food defects using RGB imaging: Application to the detection of red skin defect of raw hams. Innov. Food Sci. Emerg. Technol. 2012, 16, 417-426, https://doi.org/10.1016/j.ifset.2012.09.008.

40. Foca, G.; Salvo, D.; Cino, A.; Ferrari, C.; Lo Fiego, D. Pietro; Minelli, G.; Ulrici, A. Classification of pig fat samples from different subcutaneous layers by means of fast and non-destructive analytical techniques. Food Res. Int. 2013, 52, 185-197, https://doi.org/10.1016/j.foodres.2013.03.022.

41. Foca, G.; Masino, F.; Antonelli, A.; Ulrici, A. Prediction of compositional and sensory characteristics using RGB digital images and multivariate calibration techniques. Anal. Chim. Acta 2011, 706, 238-245, https://doi.org/10.1016/j.aca.2011.08.046.

42. Jiménez, A.M.; Sierra, C.A.; Rodríguez-Pulido, F.J.; González-Miret, M.L.; Heredia, F.J.; Osorio, C. Physicochemical characterisation of gulupa (Passiflora edulis Sims. fo edulis) fruit from Colombia during the ripening. Food Res. Int. 2011, 44, 1912-1918, https://doi.org/10.1016/j.foodres.2010.11.007.

43. Sarkar, T.; Saha, S.; Saluddin, M.; Chakraborty, R. Drying Kinetics, Fourier-Transform Infrared Spectroscopy Analysis and Sensory Evaluation of Sun, Hot-Air, Microwave and Freeze Dried Mango Leather. J. Microbiol. Biotechnol. Food Sci. 2021, 10, 1-7, https://doi.org/10.15414/jmbfs.3313.

44. Vidal, N.P.; Manful, C.F.; Pham, T.H.; Stewart, P.; Keough, D.; Thomas, R. The use of XLSTAT in conducting principal component analysis (PCA) when evaluating the relationships between sensory and quality attributes in grilled foods. MethodsX 2020, 7, 100835, https://doi.org/10.1016/j.mex.2020.100835.

45. Sarkar, T.; Salauddin, M.; Pati, S.; Sheikh, H.I.; Chakraborty, R. Application of raw and differently dried Pineapple (Ananas comosus) pulp on Rasgulla (sweetened Casein Ball) to enhance its phenolic profile, shelf life, and in-vitro digestibility characteristics. J. Food Process. Preserv. 2021, 45, e15233, https://doi.org/10.1111/jfpp.15233. 